\title{
Perception of Three-Dimensional Form From Patterns of Optical Texture
}

\author{
James T. Todd and Robin A. Akerstrom \\ Brande1s University
}

\begin{abstract}
The research described in the present article was designed to investigate how patterns of optical texture provide information about the three-dimensional structure of objects in space Four exper1ments were performed in which observers were asked to judge the perceived depth of simulated ellıpsoid surfaces under a variety of experimental conditions. The results revealed that (a) judged depth increases linearly with simulated depth although the slope of this relation varies significantly among different types of texture patterns (b) Random variations in the sizes and shapes of individual surface elements have no detectable effect on observers' judgments (c) The perception of threedımensional form is quite strong for surfaces displayed under parallel projection, but the amount of apparent depth is sightly less than for identical surfaces displayed under polar projection (d) Finally, the perceived depth of a surface is elıminated if the optical elements in a display are not sufficiently elongated or if they are not approximately aligned with one another A theoretical explanation of these findings is proposed based on the neural network analysıs of Grossberg and Mingolla
\end{abstract}

Human observers have a remarkable ability to obtain information from visual stımulation in order to perceive the layout of surfaces in the surrounding environment. In natural vision, a perceived surface can be redundantly specified by many different aspects of optical structure. The present experiments were designed, however, to examine one small component of this overall process-namely, the perception of three-dimensional form from patterns of optical texture.

The concept of texture in the study of visual surface perception was introduced almost 40 years ago in a classic series of artıcles by James Gibson (1947, 1950a, 1950b). Gibson observed that most of the surfaces encountered in nature have characteristic patterns of reflectance called surface texture, which, when illuminated by ambient light, produce cyclic patterns of luminance called optical texture at a point of observation It is useful to conceive of these two types of texture as if they were composed of elementary units. The elements of surface texture can be thought of as bounded regions of one reflectance surrounded by a background of some other reflectance, whereas the elements of optical texture can be portrayed simlarly as bounded regions of homogeneous luminance surrounded by a background of some other luminance (cf. Todd, 1984). 'Because variations in luminance within a cone of visual solid angles are directly influenced by variations in reflectance on a visible surface, the elements of surface texture and optical texture are typically in one-to-one correspondence. It is important to keep in mind, however, that their overall patterns of organization are generally quite different because of the effects of perspective.

This research was supported in part by the National Science Foundation (Grant BNS 8420143) and the Office of Naval Research

Correspondence concerning this article should be addressed to James T Todd, Department of Psychology, Brandeis University, Waltham, Massachusetts 02254
In his original analysis, Gibson assumed that patterns of surface texture are stochastically regular, so that the texture elements within equal regions of a given surface have comparable distributions of size, shape, and density. Whenever this assumption is satisfied, he argued, the structure of a surface in threedimensional space can be unambiguously specified by its corresponding pattern of optical texture. In order to understand why this is so, it is useful to consider a planar cross section of the cone of visual solid angles (1.e., a picture plane). Suppose that a surface is covered with small circular dots. Although the sizes and shapes of these dots in three-dimensional space may be identıcal, their projected sizes and shapes on the picture plane will vary as a function of two physical variables: (a) the distance of the surface from the point of observation and (b) its orientation in depth relative to the line of sight (see Figure 1). This systematic variation in the sizes and shapes of the optical texture elements provides potential information about an object's three-dimensional form.

The ability of human observers to make use of texture information was first investıgated by Gibson (1950a). The stımuli in this experiment were created by photographing a series of regular and irregular texture patterns from varyıng orientations (see Figure 2). Human observers viewed each photograph through an aperture in order to elımınate other possible sources of information (e.g., motion, disparity, accommodation or differential blur) and were asked to judge the perceived orientation of the depicted surface by using an adjustable palmboard As expected, the patterns of optical texture withın each photograph produced a strong impression of a physical surface oriented in

\footnotetext{
' Gibson would probably not have approved of this working definition of a texture element, because it does not take into account the hierarchlcally nested structure of natural textures An alternative analysis using fractal functions has recently been described by Pentland (1983), in which it is demonstrated that this nesting of structure is a potentially rich source of visual information
} 


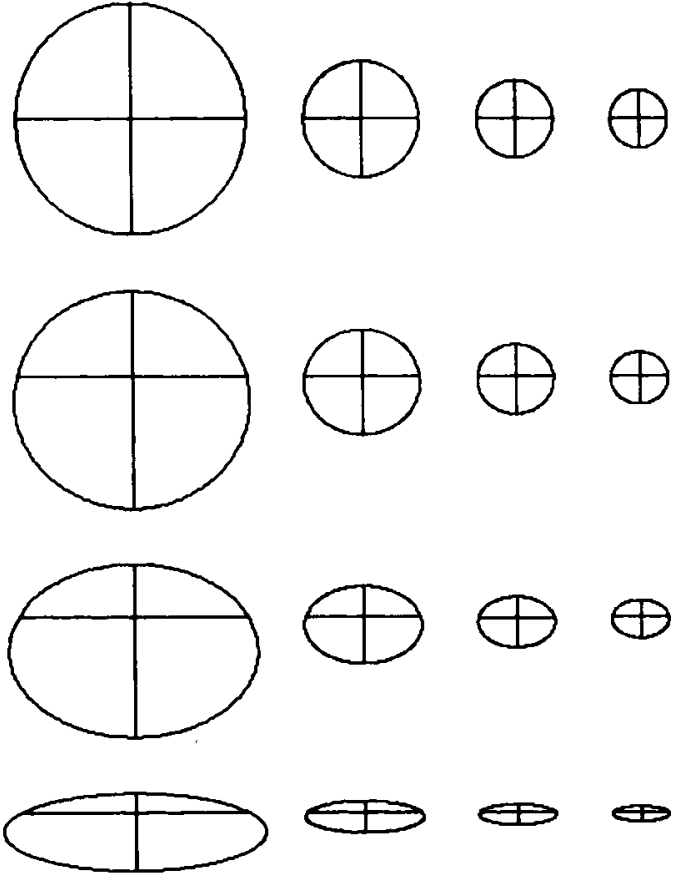

Figure 1 The effects of viewing distance and surface orientation on the polar projection of a circular texture element (The columns from left to right depict viewing distances of $1,2,3$, and 4 circle diameters, respectively The rows from top to bottom depict slant angles of $0^{\circ}, 25^{\circ}$, $50^{\circ}$, and $75^{\circ}$, respectively The projected center of each circle is represented by the point where the honzontal and vertical lines intersect The center point appears displaced in the projections of slanted circles at close viewing distances because of the convergence effects of linear perspective )

depth There was, however, a systematic tendency to underest1mate the "true" slants of the depicted surfaces, which, consistent with the assumption of stochastic regularity, was signifcantly greater for the irregular texture patterns

The first computational analysis of texture information was performed by Purdy (1958) in a doctoral dissertation done under Gibson's direction. The goal of this analysis was to demonstrate mathematically how the slant of a planar surface relative to the line of sight could be visually specified by its corresponding pattern of optical texture. The analysis considered four types of variation among optical texture elements that could potentially be informative: gradients of size (1.e., length), gradients of compression (1.e., width/length), gradients of convergence (1.e., linear perspective), and gradients of density (1.e., the number of texture elements per unit solid angle). Purdy was able to show that all four of these gradients provide equivalent information (cf. Braunstein \& Payne, 1969). In each case the slant $\theta$ of a planar surface relative to the line of sight is optically specified by the general equation

$$
\theta=\operatorname{arccot}(G / k),
$$

where $G$ is the particular gradient being analyzed and $k$ is a constant specific to that gradient.

During the 1960s, a considerable amount of research was performed in an effort to determine the relative importance of these gradients for human perception (see Braunstein, 1976, for an excellent review). The most common procedure for achieving this goal was to obtain observers' slant judgments for visual displays in which different gradients provide conflictıng information. The general pattern of results in these experiments revealed that for displays composed of granular texture patterns, the gradients of size and compression have a greater effect on observers' slant judgments than do gradients of density. For displays containıng converging line segments, however, the gradient of convergence (1.e., linear perspective) tends to dominate all other forms of texture information.

\section{Perceptual Analysis of Curved Surfaces}

Although most of this early research on the perception of surface slant from patterns of optical texture remained generally faithful to Gibson's original conception, he eventually disavowed it as he began to consider the more general problem of perceiving surface layout. His reasons for this change of view are clearly stated in the following passage from The Ecological Approach to Visual Perception (1979).

\footnotetext{
What was wrong with these experiments? In consideration of the theory of layout, we can now understand it I had made the mistake of thinking that the experience of the layout of the environment could be compounded of all the optical slants of each piece of surface I was thinking of slant as an absolute quality, whereas it is always relative Convexities and concavities are not made up of elementary impressions of slant but are instead unitary features of the layout (p 166)
}

A similar argument was later proposed by Cutting and Millard (1984) They noted that visual information about optical slant is probably of little use in a natural environment. Consider, for example, the optical slant for a planar support surface. It is perpendicular to the line of sight at one's feet, but it grades uniformly to the horizon, where it becomes parallel to the line of sight. Like Gibson, they suggested that the overall curvature or flatness of a surface is a more relevant property for the perception of object shape than is optical slant. They also performed an important series of experiments in which they measured observers' sensitivity to surface curvature from patterns of optical texture (see also Todd \& Mingolla, 1983)

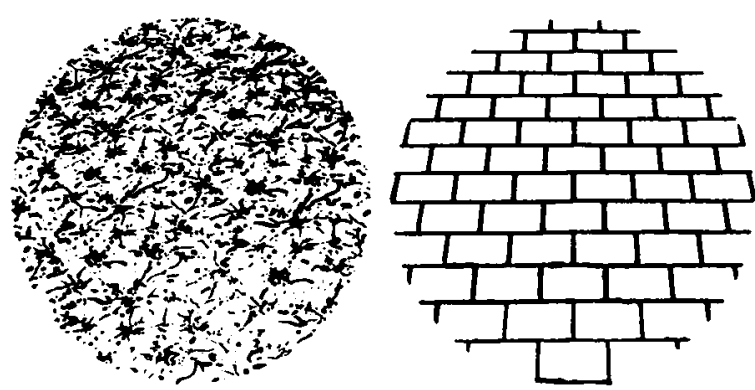

Figure 2 Two of the texture patterns used by Gibson (1950a) From "The perception of visual surfaces" by J J Gibson, 1950, American Journal of Psychology, 63, p 377 Copyright by University of Illınois Press Reprinted by permission (Each pattern depicts a planar surface at a $40^{\circ}$ slant ) 
Not all researchers, however, have been so quick to abandon a model of surface perception based on local estımates of depth and/or orientation. For example, a more classical approach to the perception of shape from texture has recently been proposed by Stevens (1981). According to Stevens, the main problem for this type of analysis is that most properties of optical texture vary with both depth and orientation and therefore cannot provide an unambiguous measure of either one. There are some exceptions, however. Note in Figure 1 that the lengths of the optical texture elements vary systematically with surface depth but remain relatively stable with changes in surface orientation The compression (1.e., width/length) of the elements shows a complementary pattern-that is, it varies with surface orientation but remains relatively stable with changes in depth. According to Stevens, these two complementary sources of information are ideally suited for the perception of three-dimensional form Local values of surface depth and onentation could be estımated directly from element lengths and compressions, without having to detect any type of texture gradient as originally suggested by Gibson.

A number of straightforward predictions follow from this analysis. It is important to keep in mind, for example, that the proposed method for estımating local surface depth is based on a rather strong assumption that the elements of surface texture on an object are of constant size Whenever this assumption is violated, the length of an optical texture element must be determined by both the size and depth of its corresponding surface element. Because optical element length would no longer be a pure measure of local surface depth, we would expect the accuracy of observers' depth judgments to be significantly diminshed. The analysis also assumes that an observed surface is viewed with a high degree of polar perspective If the viewing distance were sufficiently large to approximate a parallel projection, then the lengths of the optical texture elements would be completely independent of variations in depth, and an observer's ability to judge depth from texture should be eliminated altogether.

With respect to the estimation of local surface orientation, Stevens' analysis assumes that the elements of surface texture have an approximately circular symmetry This assumption can be violated in several ways, but, as previously noted by Witkın (1981), the perceptual effects should be partıcularly severe when the surface elements are elongated Figure 3 shows the optical projection of an elongated rectangular surface element that has been rotated $60^{\circ}$ relative to the fronto-parallel plane in three different directions. The angle formed between the surface element and the fronto-parallel plane is referred to as slant, whereas the angle of the rotation axis within the fronto-parallel plane is referred to as tilt Note in the figure that the optical effects of changes in orientation are anisotropic-that is, when a surface element is elongated, both the length and compression of its corresponding optic element vary with the direction of tilt. Because the length of an optic element is no longer a pure measure of depth and the compression of an optic element is no longer a pure measure of slant, it is reasonable to expect that - bservers' Judgments of three-dimensional form should be significantly impaired.

Although it may at first appear that the limitations of this analysis are much too restrictive to be taken seriously as a
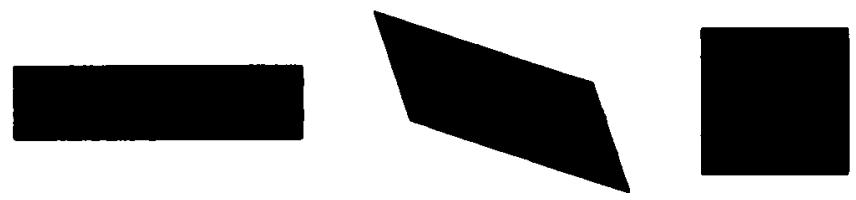

Figure 3 The optical projection of an elongated rectangular surface element at a $60^{\circ}$ slant (From left to right the depicted tilts relative to the horizontal are $0^{\circ}, 45^{\circ}$, and $90^{\circ}$, respectively)

model of human perception (see, however, Stevens, 1984), there are almost no data avallable to make a clear-cut assessment of its psychological validity, especially with regard to the perception of curved surfaces. The present series of experiments began, therefore, with an empirical test of the three predictions described above Observers' judgments of perceived depth were evaluated for computer-simulated ellipsords of varying eccentricity. The surfaces could be displayed with etther parallel or polar perspective; the sizes of the simulated surface elements could be constant or variable, and the shapes of the surface elements could be square or elongated.

\section{Experıment 1}

\section{Method}

Subjects Six Brandets University graduate students volunteered to participate in the experiment. None of the observers was familiar with the theoretical issues being investigated or the specific detals of how the displays were generated

Stımull Images were generated by using an LSI-11/23 microprocessor and displayed on a Terak 8600 graphics system The displays were observed through a viewing hood lined with black nonreflecting felt, which extended $381 \mathrm{~cm}$ from the screen This assured monocular viewing and eliminated extraneous stımulation from other parts of the laboratory. The stımuli were presented within an $18 \times 25-\mathrm{cm}$ rectangular window of the display screen The spatial resolution within this viewing wndow was $480 \times 640$ pixels Thus, each pixel had a vertical and hor1zontal extent of approximately $0038 \mathrm{~cm}$, producing a visual angle of about $3.5 \mathrm{~min}$

All of the stımulus displays depicted ellipsoid surfaces of varying eccentricity The virtual ellipsoids were defined and positioned in 3-D space in such a way that upon projection onto the center of the display screen, each surface created an identical crrcular boundary with a radius of $7.8 \mathrm{~cm}$ Two of the semi-axes of each ellipsold were parallel to the display screen, while the remaining "depth" axis was perpendicular The length of the depth axis could be manipulated so that the simulated protrusiveness of the visible portion of the surface could have possible values of $3.75 \mathrm{~cm}, 75 \mathrm{~cm}, 1125 \mathrm{~cm}, 150 \mathrm{~cm}$, or $1875 \mathrm{~cm}$. These surfaces will be referred to by their ordinal depth values numbered 1 through 5 , respectively The self-occluding boundary of the surface that determined the outer contour of its optical projection was always located in the plane of the display screen

The simulated distance between a hypothetical observer and the display screen was also manipulated In the high-perspectlve (polar) condltıon, the simulated viewing distance was $412 \mathrm{~cm}$, producing a polar projection of the surfaces Note that this closely approximated the actual viewing distance, assuming that the observers posituoned their eyes a small distance away from the end of the viewing hood In the lowperspective (parallel) condition, the simulated viewing distance was $\mathbf{3 8 0}$ $\mathrm{cm}$, thus approximating a parallel projection of the surfaces

Texture elements were randomly distributed over each virtual surface 

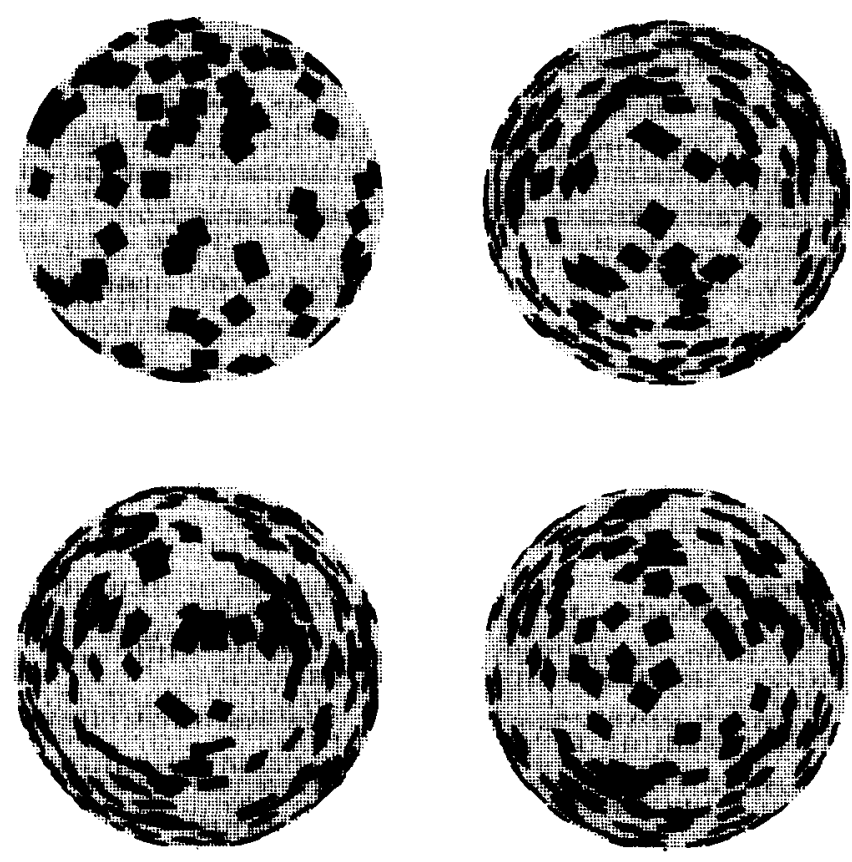

Figure 4 Examples of stimuli used in Experiment 1 (Clockwise from the upper left are a \#1 surface from the polar regular condition, a \#5 surface from the polar regular condition, a $\# 5$ surface from the parallel regular condition, and a \#5 surface from the polar irregular condition )

in random orientations, so that every point on the surface had an equal probability of being covered (see Todd \& Mingolla, 1984, for detals of the randomization procedure) After each stimulus was generated, it was checked to ensure that between $24 \%$ and $26 \%$ of its visible surface was covered by texture elements

The texture elements on the virtual surface in 3-D space were manıpulated in two ways In the regular texture condition, the elements were squares encompassing the same area In the irregular texture condition, the elements could vary randomly in both size and shape In this latter case, the area of the larger elements could be up to three times that of the smaller elements, and the length of an element could be up to three times greater than its width When size and shape were variable, the average area of the elements was the same as in the regular texture condition

The areas of the texture elements were covaried with surface eccentricity so that the maxımum size of their optical projectıons would be approximately equal in all conditions and could not be used as a confounding cue for the observers' depth Judgments In the high-perspective condition, the area (or average area) of a surface element was $397 \mathrm{~cm}^{2}$, $333 \mathrm{~cm}^{2}, 276 \mathrm{~cm}^{2}, 223 \mathrm{~cm}^{2}$, and $176 \mathrm{~cm}^{2}$, respectively, for surfaces \# 1-5 In the low-perspective condition, the elements had an area of 397 $\mathrm{cm}^{2}$ for all of the surface eccentricities

In the resulting visual images, the optical projection of a surface was always confined to a constant circular region of the display screen, agannst a black background The parts of the surface covered with texture elements were presented as white, whereas the parts of the surface not covered by texture were presented as medium gray

To summarıze, four types of stımulı were generated, each at five levels of simulated surface eccentricity, for a total of 20 displays Surfaces could have texture elements that were etther regular or irregular and could be displayed under etther polar or parallel projection Examples of some of the stimuli are shown in Figure 4 From left to right, the top row shows a \#1 and a \#5 surface, respectively, textured with regular elements and displayed under polar projection The bottom row shows a \#5 surface with irregular elements displayed under polar projection and a $\# 5$ surface with regular elements displayed under parallel projection

Procedure Subjects were seated so that they could observe the displays through the viewing hood and type responses into the computer console Each observer was specifically instructed to judge how much the simulated surface appeared to protrude out of the screen, relative to its width They were asked to make real-number responses based on a diagram provided by the experimenter, which contained a series of seven half-ellipses varying in eccentricity and labeled with a number between 0 and 6 (see Figure 5) Subjects were informed that the numeric values on the diagram were only examples of possible ratios used in the experıment and that they could choose any real number between 0 and 6 for their rating Note that the most and least eccentric surfaces that were generated corresponded to the $\# 5$ and $\# 1$ on this diagram, respectively Five practice trials were completed, during which time any questions were answered Observers rated each of the displays five tumes (order randomized between blocks of 20 trials) and made a total of 100 responses per subject

\section{Results and Discussion}

The first block of 20 trials was treated as practice and discarded for all subjects, leaving 80 depth judgments per subject for analysis. Figure 6 shows the mean depth ratıngs for each of the 20 stımuli tested in this experiment.

A withın-factors repeated measures analysis of variance (ANOVA) was performed on the remaining data, with simulated surface depth, texture regularity, and perspective serving as the factors The analysis revealed a significant effect of surface depth, $F(4,395)=7686, p<.001$, accountung for approximately $64 \%$ of the variance in subjects' judgments. Notice, however, that depth ratıngs for displays of surfaces with irregular texture elements were not significantly different from ratıngs for displays of surfaces with regular texture Another interesting finding from these data is the significant, though slight, decrease in perceived depth for surfaces displayed under parallel as compared with polar projection, $F(1,395)=10.10, p<.002$, accountıng for approximately $2 \%$ of the variance.

It is important to keep in mind when evaluating the results of this experiment, that in the regular texture condition, the lengths and compressions of the individual optic elements were

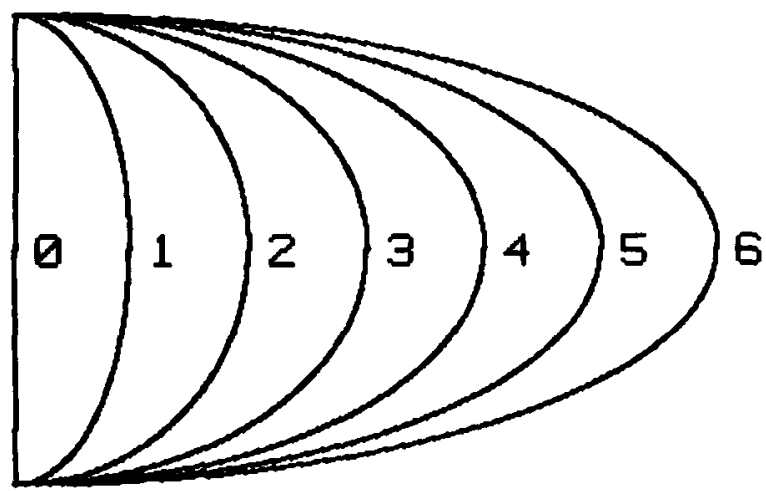

Figure 5 The cross sections of six ellipsoid surfaces used to define a numerical scale for the observers' judgments 


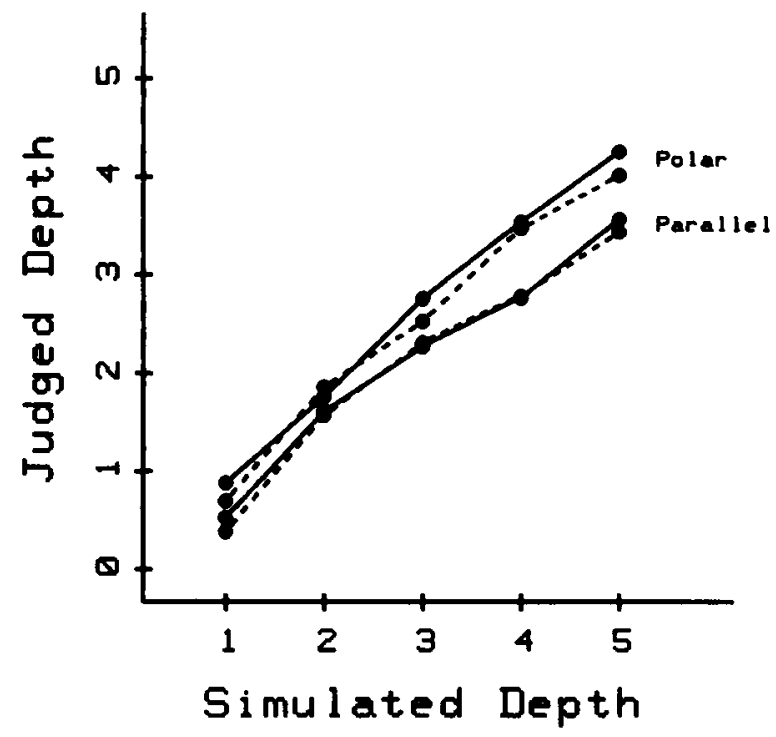

Figure 6 The mean depth judgments of 6 observers as a function of simulated depth for the different conditions of Experiment 1 (Judgments for regular and irregular texture patterns are represented by solrd and dotted lines, respectively)

highly correlated with the depths and orientations, respectively, of their corresponding surface elements. Although the strength of these correlations was significantly diminıshed in the irregular texture condition, there was no detectable impairment in the accuracy of the observers' judgments. This suggests that observers do not perceive surfaces by assigning local depth values from optic element lengths or by assigning local orientation values from optic element compressions, as argued by Stevens $(1981,1984)$ and Witkin (1981). It appears instead that the observers' judgments were based on a more global level of image structure, which could apparently provide sufficient information to overcome significant amounts of noise in the local structure of individual elements.

What are the perceptually relevant properties of individual texture elements on which the global pattern of texture is defined? This issue was recently debated in an exchange between Stevens (1984) and Cutting and Millard (1984) Stevens argued on computational grounds that lengths of elements provide the most reliable information, whereas Cutting and Millard produced empirical data that observers' judgments of curvature seem to be based almost entirely on the pattern of element compression.

The results of the present experiment are completely incompatıble with Stevens' hypothesis in this regard. The displays presented under parallel projection were designed specifically to elımınate any systematic variations in element length, yet the observers' judgments of those displays were only slightly less accurate than in the polar condition. The results are consistent, however, with Cuttıng and Millard's hypothesis. Figure 7 shows the pattern of element compression as a function of position for $\mathrm{a} \# 1$ and $\mathrm{a} \# 5$ surface under both polar and parallel projection. Note in the figure that a change from polar to parallel perspective influences the pattern of compression in exactly the same way as does a small decrease in surface depth-Just as it affected the observers' judgments.

Although it is tempting to conclude on the basis of these findings that the overall pattern of element compression was the primary source of information for the observers' judgments, it is important to keep in mind that there were several other confounding variables in these displays that covaried with compression. If element width or area were plotted agaunst position, for example, the resulting curves would be identical to those shown in Figure 7. Experiment 2 was designed, therefore, in an effort to manipulate some of these variables independently of one another.

\section{Experiment 2}

\section{Method}

The method for generatıng ellipsoid surfaces was identical to that used in Experiment 1. For this experıment, however, some of the manipulatrons were done on the optic elements rather than the elements on the virtual surface

In each of five texture conditions, five surface depths $-3.75 \mathrm{~cm}, 75$ $\mathrm{cm}, 1125 \mathrm{~cm}, 15.0 \mathrm{~cm}$, and $1875 \mathrm{~cm}$-were simulated to protrude as before out of the display screen (numbered 1 through 5, respectively), for a total of $\mathbf{2 5}$ displays In the polar and parallel regular conditions, surfaces with regular texture elements (of constant size and shape) were displayed under polar and parallel projection, respectively These two types of displays replicated two of the conditions used in Experiment 1 and were included as a means of comparing depth judgments made for them with responses to the other three conditions described below In the next three conditions the surface texture was regular, and all surfaces were displayed under polar projection The difference among these conditions, however, was that upon projection the optical texture pattern was manupulated as follows In the constant area condition, the pattern of optical element compression was allowed to vary appropriately. Compression occurred in a direction perpendicular to the tilt of the virtual

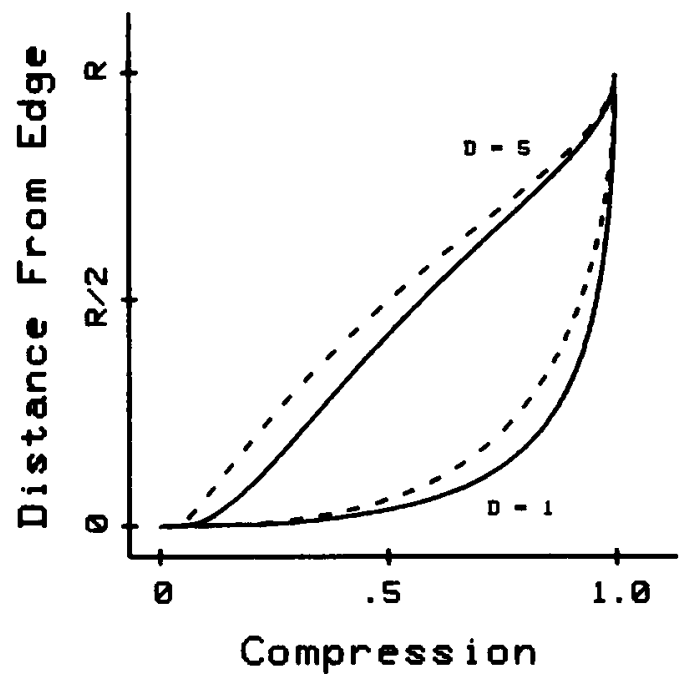

Figure 7 Element compression plotted against position for a \#1 and a \#5 surface in two of the conditions from Experiment 1 (The dotted lines represent polar projections, and the solid lines represent parallel projections The radius $[R]$ of each circular texture pattern defines the units along the vertical axis $D=$ surface depth ) 
surface and hence varied in the correct orientation Optical element area was held constant, however, so that, in effect, the optical elements tended to become progressively enlarged as their position neared the edge of the image The displays generated for the random orientation condition were the same as for constant area condition (area held constant with compression varying), except that after each optic element was appropriately compressed, its orientation in the display screen was then randomized This manipulation was included to determine the relative importance of correct optical element orientation Finally, in the constant compression condition, the pattern of optucal element compression was held constant while area was allowed to vary appropriately In effect, the texture on these images looked like squares that became progressively smaller toward the edges of the display Figure 8 shows some examples of the stimuli used in this experiment Each of the four figures depicts a \#5 surface under polar projection. Moving clockwise from the upper left, exemplars are presented from the constant area condition, the polar regular condition, the random orientation condrtion, and the constant compression condition

To summarize, surfaces at each of five simulated depths were generated with each of five texture conditions, for a total of 25 displays In the first two conditions, surfaces with regular texture elements were displayed under either polar or parallel projection In two other conditions, optic elements were manipulated in such a way that area was held constant and compression varied either in the appropriate or at random orientations In the last condition, optic element compression was held constant while area varied appropriately over the displays

Six Brandeis University graduate students participated in this exper1ment, 4 of whom had also participated in Experiment 1 Observers made depth judgments for each of the 25 displays four times in a randomized block design, for a total of 100 responses per subject The instructions and procedures used were identical to those used in Experiment 1

\section{Results and Discussion}

The first block of 25 trials per subject was discarded as practice Mean depth judgments for each of the 25 stımulı were cal-
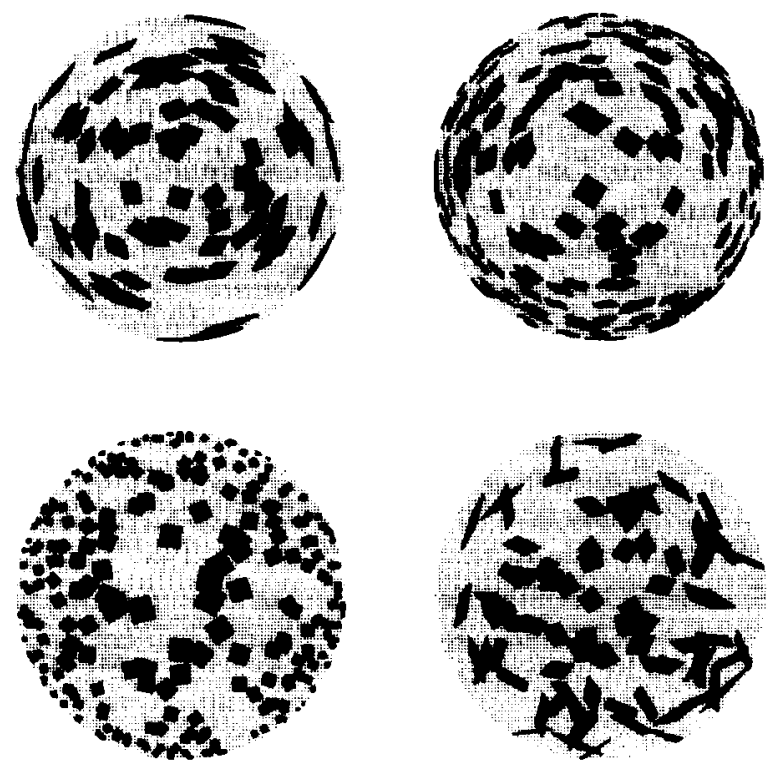

Figure 8 Examples of stımulı used in Experiment 2 (Clockwise from the upper left are \#5 surfaces from the constant area condition, polar regular condition, the random orientation condition, and the constant compression condition)

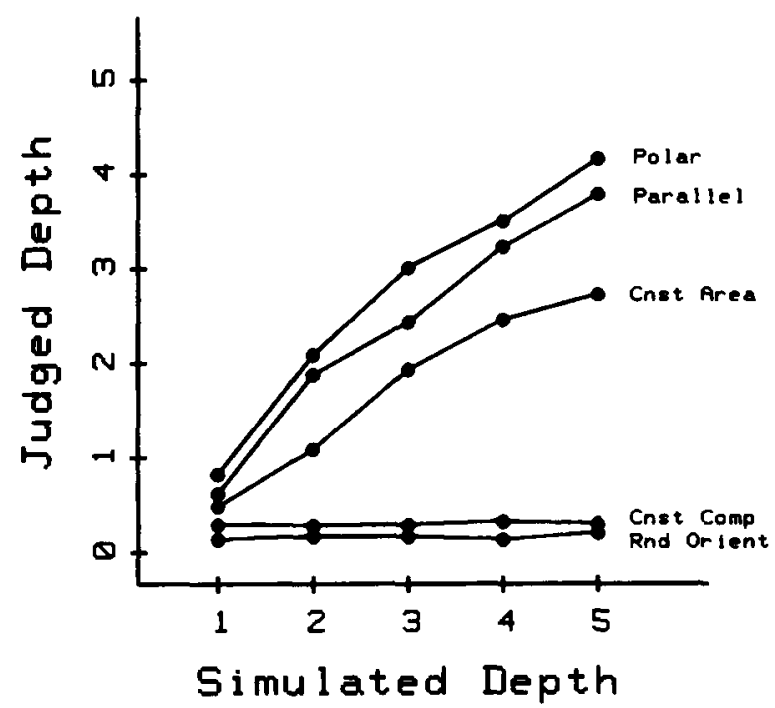

Figure 9 The mean depth judgments of 6 observers as a function of simulated depth for the different conditions of Experiment 2 (Cnst area $=$ constant area condition, Const Comp $=$ constant compression condition, Rnd Orient = random orientation condition )

culated from the remaining data and plotted in Figure 9 as a function of simulated surface depth

In the discussion of Experiment 1, it was suggested that the observers' judgments of depth were probably based on the global pattern of element compression but that other possible optic variables such as element width and area were confounded with compression and could not be eliminated as possible sources of information The present experiment was designed, therefore, to manipulate these different variables independently of one another.

If variations in element compression are indeed responsible for observers' perceptions of curved surfaces, then a display in which all elements have a constant compression should be perceived as flat. This prediction is clearly confirmed by the results of the present experıment. In the constant compression condition, the mean depth ratıng for a $\# 5$ surface was only 0.21 , even though there were systematic variations in element length, width, area and density, which could, in principle, have provided information about the surface's three-dimensional form One would also expect that if observers' judgments were based solely on the pattern of element compression, then orthogonal manipulations of other variables should have no effect on performance. This prediction, however, was not confirmed by the results of the experiment. Although the pattern of element compression was identical in both the constant area and the polar regular conditions, the observers' judgments were quite different. Eliminating variations in area produced a $37.8 \%$ reduction in perceived depth, which suggests quite strongly that there is more to the perception of shape from texture than can be adequately explained by a simple compression hypothesis.

We also included one final condition in an effort to determine if compression is best considered as a vector with both magnitude and direction or as a scalar with magnitude only. The basic idea was to randomly reorient the texture elements in the image 
plane to eliminate their directional alignment with one another This had a dramatic effect on observers' judgments. The mean depth rating of a \#5 surface in the random orientation condition was only 020 , thus suggesting that the orientational alıgnment of texture elements is a necessary condition for the perception of a curved surface

The results obtained at this stage in the investigation placed us in a quandry Many of the findings seemed to be consistent with Cuttıng and Millard's (1984) hypothesis that the perception of a curved surface in depth is determined primarily by the overall pattern of element compression One finding, however, was clearly anomalous when viewed from this perspective. There were large differences in perceived depth between the polar regular and constant area conditions, yet the patterns of element compression in those conditions were identical. An adequate explanatıon of these seemingly contradictory findings did not emerge until we began to consider some possible mechanisms for the pickup of texture information.

Perceptual mechanisms for the analysis of texture There are two important sources of evidence that the perceptual analysis of texture information is accomplished by a fundamentally global process First, there is the finding from Experiment 1 that local perturbations in the sizes and shapes of individual texture elements have almost no effect whatsoever on the accuracy of observers' depth judgments (see also Cuttıng \& Millard, 1984) A second relevant finding is that each display was experienced as a continuous, smoothly curved surface, even though the texture elements covered only $25 \%$ of its visible area

One possible process for detecting the global pattern of optcal texture has recently been described in an important series of articles by Grossberg and Mingolla (1985a, 1985b). Although their work has been primarly concerned with two-dimensional perceptual organization (e.g., subjective contours and perceptual grouping phenomena), it is also ideally suited for the analysis of texture patterns such as those used in the present experıments Accordıng to Grossberg and Mingolla, many of the known phenomena in low-level visual perception can be elegantly explained by the dynamic properties of neural networks, in which the individual neurons are tuned to specific spatial frequencies and orientations. Much of this explanatory power comes from a subtle interplay between two interacting systems a feature contour system, which diffuses information in all directions throughout the network, and a boundary contour system, which fills in and completes optical contours to form a barrier for this diffusion It is the boundary contour system, we believe, that is largely responsible for the perception of shape from texture.

A schematic diagram of the boundary contour system is shown in Figure 10. As described by Grossberg and Mingolla, the system consists of two stages' The first stage is characterized by short-range local competition between cells with different orientational tuning. If any incoming signals survive this competition, they are passed to a second stage of analysis, in which there is long-range cooperation of cells with similar orientational tuning. Activity at this level is then fed back to the first stage, which achieves a sort of filling-in process. This is how the model accounts for subjective contours and perceptual grouping phenomena It is also assumed that these boundary contours can form at several different spatial frequencies independently
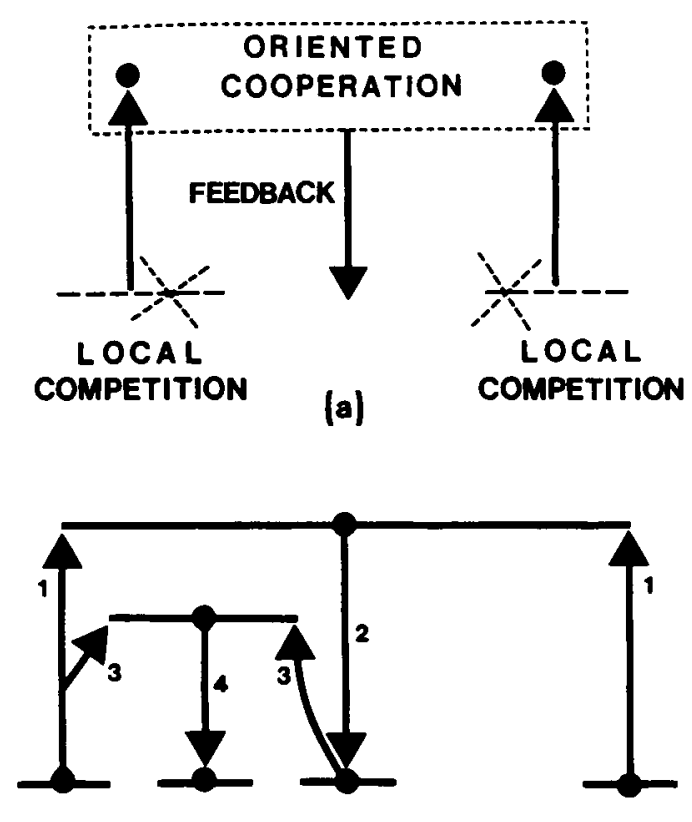

(b)

Figure 10 Boundary completion in a cooperative-competitive feedback exchange (CC loop). Panel a Local competition occurs between different orientations at each spatial location (A cooperative boundary completion process can be activated by pairs of aligned orientations that survive their local competitions This cooperative activation initiates the feedback to the competitive stage that is detailed in Figure 10b ) Panel b The pair of Pathways 1 activate positive boundary completion feedback along Pathway 2 Then pathways such as 3 activate positive feedback along pathways such as 4 Rapid completion of a sharp boundary between pathways 1 can hereby be generated (From Grossberg \& Mingolla, 1985a. From "Neural dynamics of form perception Boundary completion, illusory figures, and neon color spreadıng" by S Grossberg and E Mingolla, 1985, Psychological Revew, 92, p 187 Copyright 1985 by American Psychological Association Reprinted by permıssion )

of one another This allows the system to detect simultaneously the global structure of a texture pattern as well as the local structure of its individual elements

Let us now consider how such a system would respond to the regularly textured \#5 surface shown in Figure 4. Notice in the figure that most of the elements are noticeably compressed and that they are approximately aligned with one another. According to the Grossberg and Mingolla model, these orientationally aligned elements should form bands of activity within the boundary contour system. The spatial frequency of these bands would be expected to vary as a function of position, so that high-frequency neurons would be activated by the narrowest elements near the edge, and the low-frequency neurons would be activated by the wider elements closer to the center. ${ }^{2}$ We be-

\footnotetext{
${ }^{2}$ Grossberg and Mingolla have recently confirmed these predictıons with a numerical simulation of how their model would respond to the various texture patterns used in the present investıgations A preliminary report of this work is presented in Grossberg and Mingolla (in press)
} 
lieve that the spatial distribution of these bands of activity is responsible for the observers' perceptions of three-dimensional form.

A particularly important implication of this model is that some parts of an image may have a greater effect on the boundary contour system than may others. The reason for this is that the amount of competition at the first stage of analysis is negatively related to the amount of element compression It is important to keep in mind that any given texture element will stimulate a large number of different neurons tuned to all possible orientations. The level of competition at the first stage of analysis is determined by the relative imbalance of this stımulation If all orıentations are activated equally, as will occur with an uncompressed element, then they will all be suppressed by the local competition. If, on the other hand, one orientation is stımulated to a much greater extent than are others, as will occur with a highly compressed element, then it is much more likely to survive the resulting competitive interactions. It follows from this analysis that activity within the boundary contour system can be produced only by regions of an image in which there is sufficient element compression. This suggests, moreover, that regions near the center of an image, where element compression is negligible, may be providing httle or no information for the observer's perceptions of three-dimensional form

Another important implication of the Grossberg and Mingolla model is that the overall response of the system can be highly tolerant of noise. The reason for this is that orientational tuning of visual neurons is never absolute. Although a given cell may have a preferred onentation, it will also respond with varying degrees of vigor to contours whose orientations differ slightly from the preferred value. As a result, the cooperative interactions at the second stages of analysis are able to occur even when the contours in a stimulus pattern are not perfectly aligned with one another. This cooperation will be enhanced, moreover, by the approximate alignment of other contours in neighboring regions. As these cooperative interactions start to propagate throughout the network, the response of each cell may no longer be determined by the pattern of stimulation within its own receptive field, but will be driven instead by the statistical properties of a more globally defined pattern of input. There are limits, however, to the amount of misalignment that can be tolerated. If it is too large, as in the random onentation condition of Experiment 2, then the cooperative interactions at the second stage of analysis cannot be initiated

In order to appreciate how the pattern of activity withın the boundary contour system could provide information about the three-dimensional structure of a curved surface, it is useful to consider how the spatial frequency of the elements varies with position for some of the stimuli used in the present experiments. Figure 11 shows the relation between element width (i.e., spatial frequency) and position for a \#1 and a \#5 surface under both polar and parallel projection. Note in the figure that the spatial distribution of element widths varies significantly among the different surfaces. A convenient metric for describing these differences can be obtained by calculating the area under each curve As is evident from the figure, this area measure increases with surface depth and is sightly diminished when a surface is displayed under parallel projection. Note that this is similar to

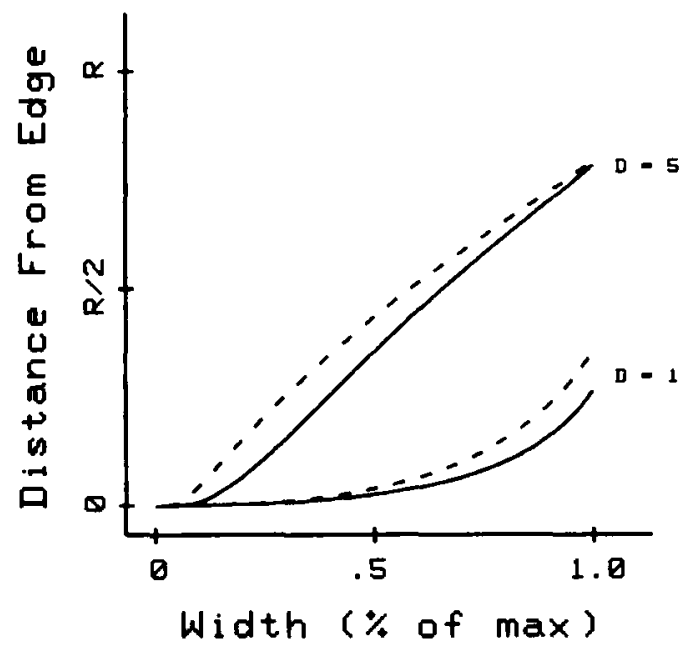

Figure 11 Element width plotted against position for a \#1 and a \#5 surface in two of the conditions from Experiment 1 (Each curve was generated with an assumed compression threshold of 875 The dotted lines represent polar projections, and the solid lines represent parallel projections The radius $[R]$ of each circular texture pattern defines the units along the vertical axis $\mathrm{D}=$ surface depth )

the pattern obtained from the observers' judgments. In fact, when the area measures for the different stımul in Experıment 1 are correlated with the observers' judgments for those stımul, the analysıs reveals an almost perfect linear relation $(r=.99)$.

Four important properties of the Width $\times$ Position curves shown in Figure 11 need to be explicitly noted. First, the width values refer to the shortest axis of an idealized optical element at each possible position within the overall stimulus pattern. If the element widths were measured in an actual stımulus, the values obtained would provide a sample of these idealized distributions. There would also be some noise in the sample because of random variations in the orientations of the surface elements. Second, it is assumed that the boundary contour system will not respond to regions of an image where the elements are insufficiently elongated, which is why the curves have a limited extent along the vertical (position) axis (A compression threshold of .875 was selected for generating these curves because it produced the best possible fit to the data in all four experıments.) Third, the width scale is normalized as a percentage of maximum width. This ensures that the area measure is sensitive only to the global pattern of width changes and not to the absolute size of a texture element. Finally, it is also assumed that the elements of optical texture are approxımately aligned with one another in any given local region. Otherwise, the activity within the system would be suppressed by local competition at the first stage of analysis

Although the area measure described above corresponds quite closely to the observers' judgments in Experiment 1, it is important to keep in mind that there were several confounding variables in that experıment (e.g., the pattern of element compression), all of which could provide equally good fits to the data. A more powerful assessment of the model can be obtanned from Experiment 2, in which these different varıables were manupulated independently of one another As it turns out, the 


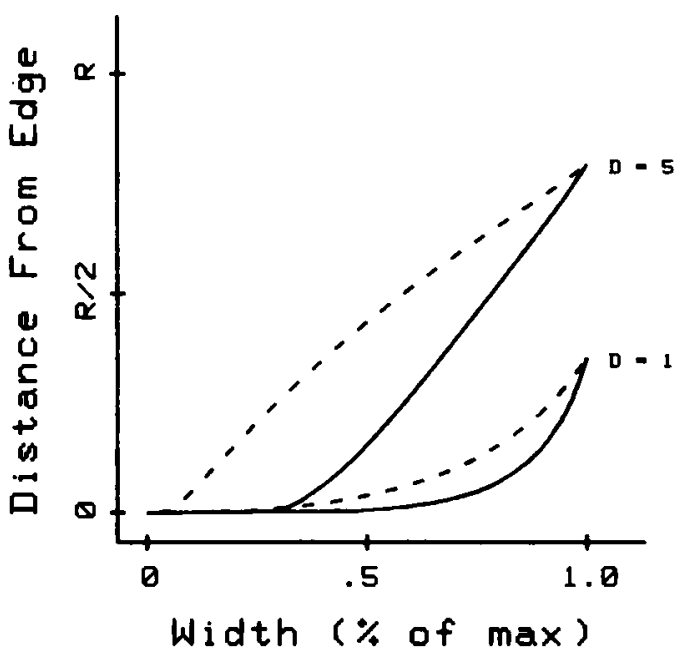

Figure 12 Element with plotted against position for a \#1 and a \#5 surface in two of the conditions from Experiment 2 (Each curve was generated with an assumed compression threshold of 875 The dotted lines represent stimul from the polar regular condition, and the solid lines represent stımuli from the constant area condition $D=$ surface depth )

area measures for the stımulı in Experiment 2 were again almost perfectly correlated with the observers' depth judgments $(r=.99)$

There are three new conditions in Experiment 2 that need to be examined Figure 12 shows the Width $\times$ Position curves for a \#1 and a \#5 surface in the constant area condition, compared with the same surfaces in the polar regular condition. Note in the figure that the area under each curve corresponds quite closely to the pattern exhibited in the observers' depth judgments (see Figure 9). In the other two conditions, the depicted surfaces should have appeared perfectly flat-as indeed they did-because they violated the restrictions of the model. In the random orientation condition, for example, the misalignment of the texture elements would have prevented the formation of boundary contours because of local competition at the first stage of analysis and should, therefore, have inhibited the perception of a curved surface in depth. A similar explanation is also applicable to the absence of perceived depth in the constant compression condition. The formation of boundary contours would be suppressed in this case because the elements were not sufficiently elongated for a predominant orientation to emerge from the resulting competitive interactions within the network.

This explanation of the observers' judgments in the constant compression condition contrasts sharply with our original interpretation that the perception of shape from texture is primarily based on global variations in optic element compression According to the Grossberg and Mingolla model, the absence of percelved depth in this condition would not be due to the lack of variations in element compression, but rather to the use of unelongated square elements, so that there was no predomınant orientation in any local region of the image. This leads to a very straightforward hypothesis-namely, that if we elongate the elements in the constant compression condition in such a way that they are locally aligned with one another, the perceived depth of a surface should be significantly enhanced. Expenment 3 was designed, therefore, in an effort to test the psychological valıdity of this prediction

\section{Experiment 3}

\section{Method}

The method for generating ellipsord surfaces was similar to that used in the previous experiments Four texture conditions were generated at each of the five levels of simulated surface depth, for a total of 20 displays. In the polar and parallel regular conditions, the stımulı were identical to those used in comparable conditions of Experiments 1 and 2 In the constant compression square condition, element area varied appropriately for polar projection, but each of the elements had an identical square shape These displays were, in fact, taken from the constant compression stımul used in Experiment 2 In the constant compression elongated condition, the patterns were generated in the same way except that each element was elongated parallel to the direction of tilt with a 31 compression ratio Figure 13 shows examples of $\# 5$ surfaces in the constant compression square (left) and the constant compression elongated (right) conditions Note that these two displays were generated in exactly the same way except the stımulus to the right had elongated elements.

Six of the observers who had participated in the previous experiments again volunteered their services Each observer made five depth judgments for all 20 displays in a randomized block design, for a total of 100 responses per subject The instructions and procedures were identical to those used in Experıments 1 and 2

\section{Results and Discusston}

The first block of 20 trials was discarded as practice, and the mean depth judgments for the remaining responses were calculated for each of the stımulı The results are plotted in Figure 14

The main purpose of this experiment was to compare two alternative hypotheses about why stimuli in the constant compression square condition should appear as flat. One hypothesis based on the work of Cutting and Millard (1984) is that the primary source of information for the perception of a curved surface is the overall variation of element compression. Patterns in which there are no such variations should therefore be perceived as flat, regardless of whether the elements are square or elongated.

An alternative hypothesis based on the work of Grossberg and Mingolla (1985a, 1985b) is that the primary source of informa-
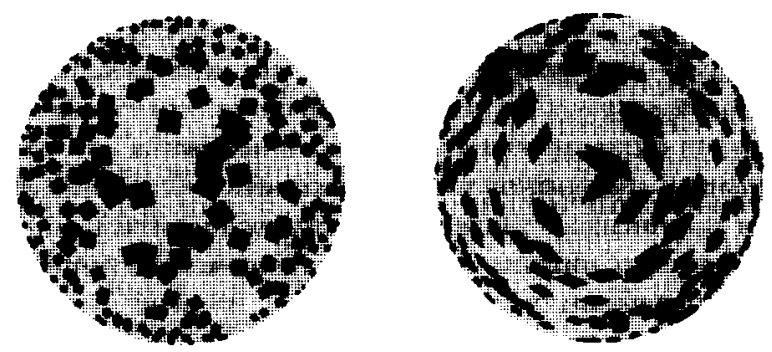

Figure 13 Examples of stimulı used in Experiment 3 (From left to right are \#5 surfaces from the constant compression square condition and the constant compression elongated condition ) 


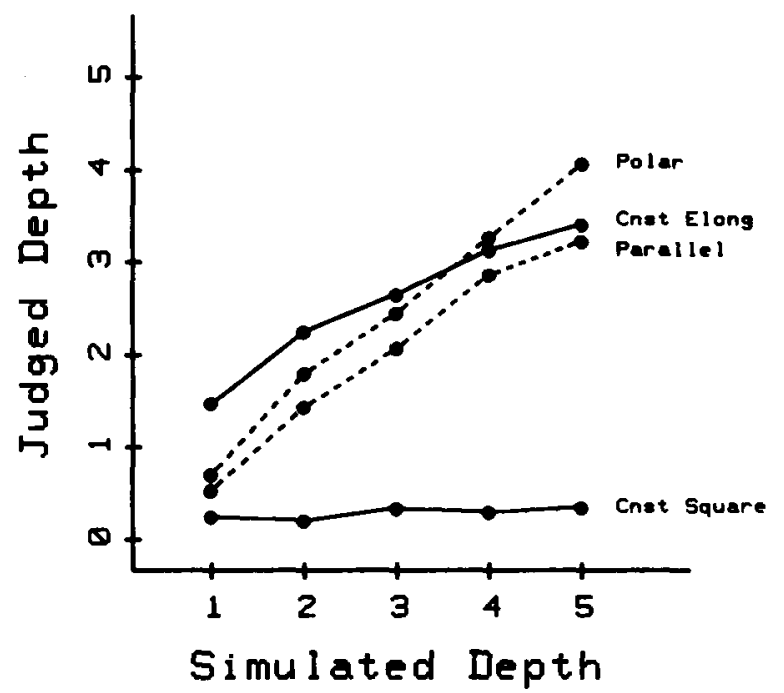

Figure 14 The mean depth judgments of 6 observers as a function of simulated depth for the different conditions of Experiment 3 (Const Elong = constant elongated condition; Const Square $=$ constant square condition )

tion in these displays is the overall variation of element widths, but only for those elements that are sufficiently elongated and approximately aligned with one another. According to this hypothesis, the stimuli in the constant compression square condition are perceived as flat, not because of the constant compression, but because the patterns are composed of unelongated square elements. This would not be a problem, however, in the constant compression elongated condition, and we would therefore expect the observers' depth judgments in that case to increase significantly. This prediction was, in fact, confirmed by the data, as is clearly evident in Figure 14.

Let us now consider how our proposed area measure would be affected by these manipulations. Figure 15 shows the variations of element width as a function of position for $a \# 1$ and a \#5 surface in both the polar regular and constant compression elongated conditions. If we calculate the area under each curve, as in the previous experıments, an interestung interaction is obtained. For a \#5 surface, the area measure is larger for the polar regular stımulus, whereas for a \#1 surface it is larger for the constant compression stimulus. A similar reversal was also obtained in the observers' judgments (see Figure 14). Indeed, when the area measures for all of the different stımuli in this experiment were correlated with the observers' depth Judgments for those stımuli, the analysis again revealed an almost perfect linear relation $(r=.99)$.

\section{Experiment 4}

Another important implication of the Grossberg and Mingolla model for the present experiments is that some parts of an Image may have a greater effect on observers' judgments than others. Note, for example, in Figure 4 that there are regions near the center of each stumulus where element compression is negligible. If observers' sensitivity is restricted to patterns of elongated elements, as we have argued above, then the texture in those regions should provide little or no information for the perception of a curved surface in depth This implication is especially significant for generating the Width $\times$ Position curves shown in Figures 11, 12, and 15 The reason that these curves generally do not extend the full length of the vertical (position) axis is that they are generated with an assumed compression threshold of .875 , which excludes from consideration the relatively unelongated elements in the central region of each display.

According to our proposed analysis, it should be possible to enhance the impression of depth in the regular texture conditions by systematically elongating the elements in these central regions. Suppose, for example, that we stretched each element in a display by a factor of 14 parallel to the direction of tilt The effects this would have on the Width $\times$ Position curves for a \#1 and a \#5 surface are shown in Figure 16, in which regular patterns are represented by dotted lines and elongated patterns are represented by solid lines. As is evident in the figure, a un1form elongation of the texture elements should increase the perceptually detectable range of element widths and should therefore produce a corresponding increase in observers' depth judgments. Experiment 4 was designed to test this prediction.

\section{Method}

The method for generatıng ellipsold surfaces was similar to that used in the previous experiments Four texture conditions were generated at each of five levels of surface depth, for a total of 20 displays In the polar and parallel regular conditions, the stimuli were identical to those used in the comparable conditions of Experiments 1, 2, and 3 In the polar and parallel elongated conditions, the stımul were generated in the same way, but each element was elongated by a factor of 14 parallel to

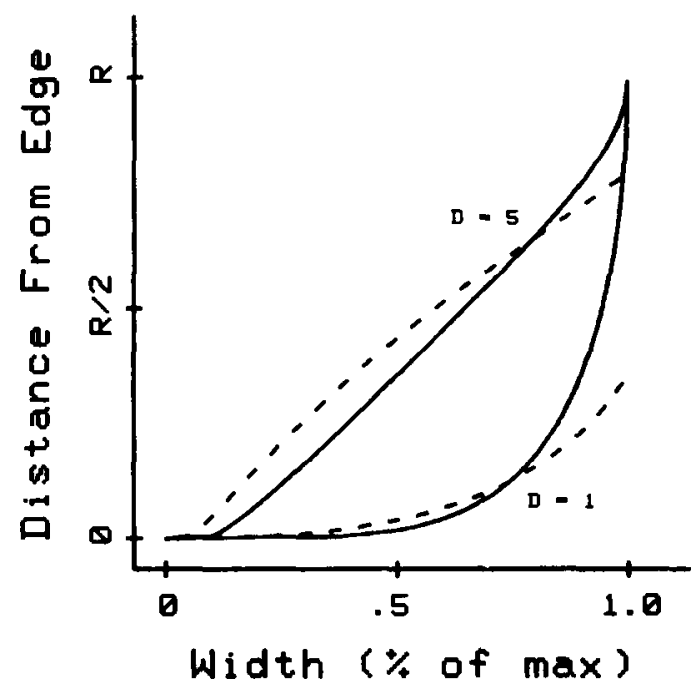

Figure 15 Element width plotted against position for a \#1 and a \#5 surface in two of the conditions from Experiment 3 (Each curve was generated with an assumed compression threshold of 875 The dotted lines represent stımuli from the polar regular condition, and the solid lines represent stimuli from the constant compression elongated cond1tion The radius [R] of each circular texture pattern defines the units along the vertical axis $D=$ surface depth ) 


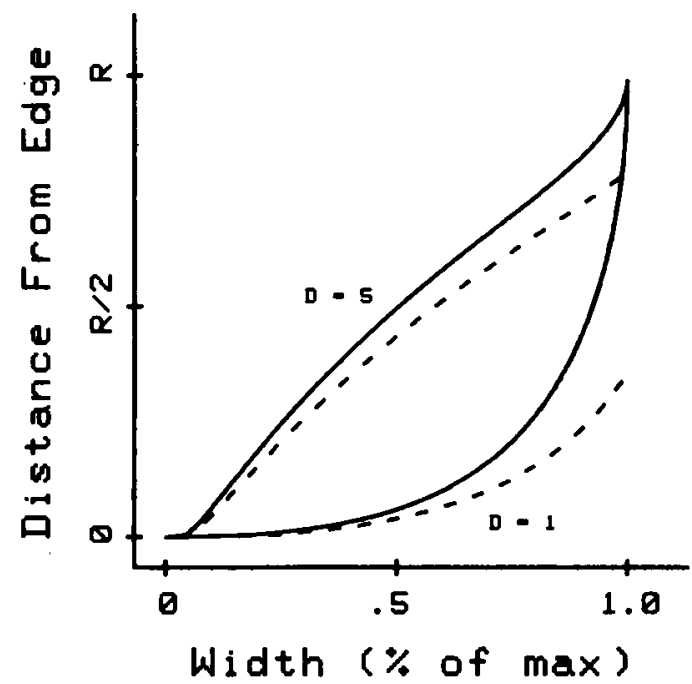

Figure 16 Element width plotted against position for a \#1 and a \#5 surface in two of the conditions from Experiment 4 (Each curve was generated with an assumed compression threshold of 875 . The dotted lines represent stimuli from the polar regular condition, and the solid lines represent stimulı from the polar elongated condition The radius $[R]$ of each circular texture pattern defines the units along the vertical axis $\mathrm{D}=$ surface depth )

the direction of tilt Figure 17 shows a \#1 surface (left) and a \#5 surface (right) from the polar elongated condition.

Six observers volunteered their services, 5 of whom had participated in at least one of the earlier experiments. Each observer made five depth judgments for all 20 displays in a randomized block design, for a total of 100 responses per subject The instructions and procedures were identical to those used in the previous three experiments

\section{Results and Discussion}

As in the previous experıments, the first block of 20 trials was discarded as practice Figure 18 shows the means of the remaining judgments as a function of simulated depth for the regular and elongated conditions collapsed over perspective. A repeated measures ANOVA was performed on these data with simulated surface depth, perspective, and elongation as the within-factor variables. The analysis revealed that the primary influence on the observers' judgments was the simulated surface depth, $F(4,395)=102.09, p<.001$, accounting for over $68 \%$ of
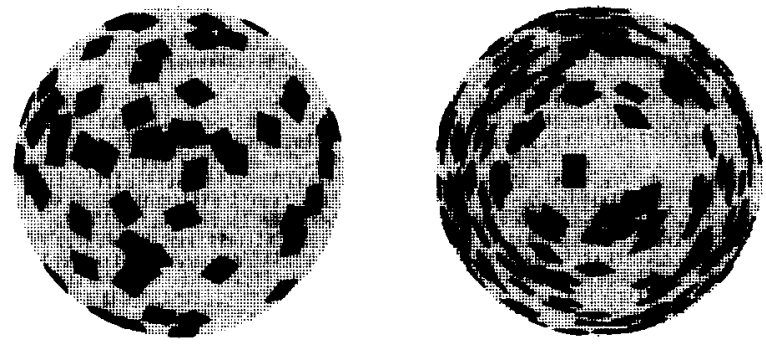

Figure 37 Examples of stımulı used in Experıment 4 (From left to right are $\mathrm{a} \# 1$ and $\mathrm{a} \# 5$ surface from the polar elongated condition )

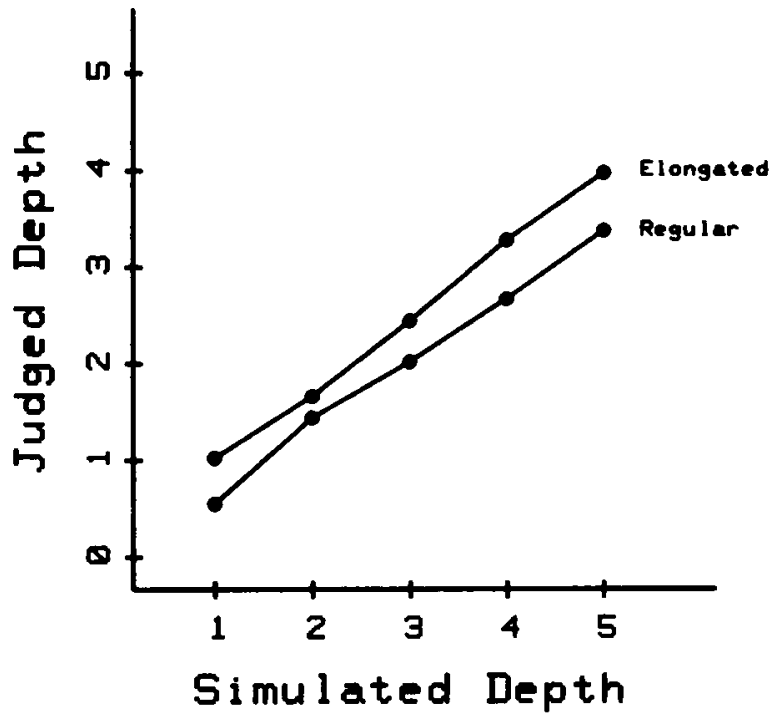

Figure 18 The mean depth judgments of 6 observers as a function of simulated depth for the regular and elongated conditions of Experiment 4 collapsed over perspective

the total variance The polar projections again produced higher depth judgments than did the parallel projections, $F(1,395)=$ $11.77, p<.001$, accounting for $2 \%$ of the variance, and the elongated conditions produced higher judgments than did the regular conditions, $F(1,395)=19.20, p<.001$, accounting for $3 \%$ of the variance. Although the effect of elongation was relatıvely small in terms of the amount of variance it accounted for, its magnitude was consistent with our theoretical predictions. Indeed, the observers' judgments were again almost perfectly correlated with the areas under the Width $\times$ Position curves $(r=99)$.

\section{General Discussion}

The research described in the present article was designed to investigate how patterns of optical texture provide information about the three-dimensional structures of objects in space. $\mathrm{Ob}$ servers were asked to judge the perceived depth of simulated ellipsoid surfaces under a variety of experimental conditions. The results revealed that (a) judged depth increases linearly with simulated depth although the slope of this relation varies significantly among different types of texture patterns. (b) Random variations in the sizes and shapes of individual surface elements have no detectable effect on observers' judgments. (c) The perception of three-dimensional form is quite strong for surfaces displayed under parallel projection, but the amount of apparent depth is slightly less than for identical surfaces displayed under polar projection. (d) Finally, the perceived depth of a surface is eliminated if the optical elements in a display are not sufficiently elongated or if they are not approximately aligned with one another.

\section{What is the "Information" in a Textured Image?}

The first issue that needs to be addressed in providing a theoretical explanation of these findıngs is to determıne the specific 


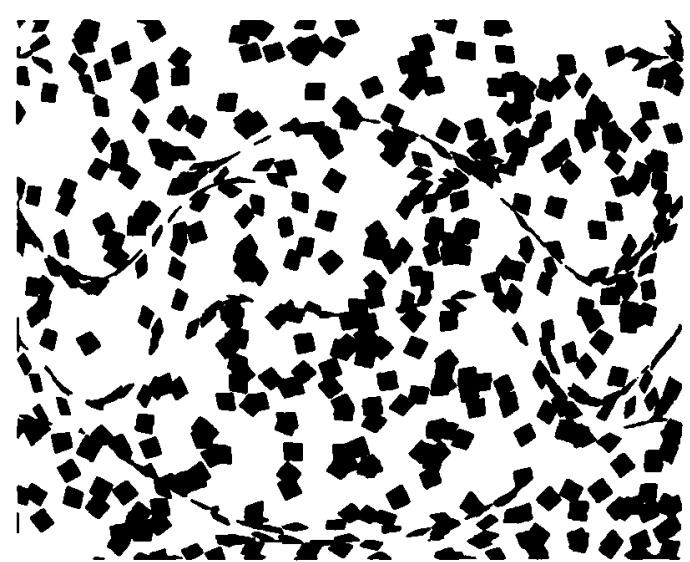

Figure 19 A complex undulating surface depicted with texture information

aspects of optical texture from which observers perceive the three-dimensional structures of curved surfaces. One important facet of this issue concerns the relative spatial scale of texture information Stevens (1984) has recently argued, for example, that the perceptual analysis of texture involves a local process, in which metric values of surface depth and/or slant are estımated directly from the sizes and shapes of individual texture elements and that higher order (1.e, relational) measures of texture, such as gradients, are unnecessary. Our results suggest, however, that the perception of shape from texture in actual human observers is probably based on a more global level of analysis. Of partıcular importance in this regard is the finding from Experıment 1 that local variations in the sizes and shapes of individual surface elements have almost no effect on the accuracy of observers' judgments. An individual texture element carries no information in this context, yet the systematic variatıons among a population of elements can apparently provide sufficient information to optically specify the three-dimensional structure of a curved surface in depth.

Having concluded that the perception of shape from texture involves relational measures of some sort, we took the next step of determınıng exactly what those relations are. Because of the earher work of Cutting and Millard (1984), our workıng hypothesis at the start of this investigation was that the primary source of information for the observers' judgments would be the global pattern of element compression. Our initial findings were, in fact, consistent with this hypothesis Changes in perspective and depth, which had comparable effects on the pattern of element compression, also had comparable effects on the observers' judgments. Moreover, when other properties of the optic elements-such as length, width, area, and density-were allowed to vary over different regions of a display but compression was held constant, the appearance of depth was virtually elımınated There were other aspects of the data, however, that seemed to require an alternative explanation. In Experiment 2, there were large differences in perceived depth between the polar regular and constant area conditions, yet the patterns of element compression in those conditions were identical.

How could we account for these seemingly incompatible results? A solution to this dilemma was suggested in a series of conversations with Stephen Grossberg and Ennıo Mingolla (personal communication, August, 1985). Based on their neural network analysis of low-level visual processes, they speculated that the observers' judgments were probably based on the global pattern of element widths. At first we were highly skeptical of this hypothesis. After all, there were systematic variations of element width in the constant compression condition of Exper1ment 2, but they did not provide a compelling impression of a curved surface in depth. The reason for this, according to Grossberg and Mingolla, is that the neural mechanisms for detecting variations in element width can respond only if the elements are sufficiently elongated To test this hypothesis in Experiment 3 , we employed a new series of displays with elongated elements of constant compression. As predicted, the perceived depth in these displays was comparable to the regular texture conditions, whereas the patterns of square ( $\mathrm{e}$, unelongated) elements were again perceived as flat. Another implication of the Grossberg and Mingolla hypothesis is that a uniform elongation of all the elements in a display should increase the detectable variation of element widths and should therefore produce a significant increase in perceived depth. This prediction was confirmed by the results of Experiment 4.

The neural network analysis proposed by Grossberg and Mingolla can be thought of as a type of transduction mechanism by which discrete patterns of stımulation are transformed into a relatively continuous pattern of neural activity. The analysis suggests a number of relevant stımulus variables that should affect this transduction process, but it does not provide an explıcitly defined procedure for assigning a meanıngful interpretation to any given pattern of stımulation. How, for example, did the observers in our experiments select a specific depth value for each stımulus display? In an effort to address this issue and to provide a more quantitative analysis of the data, we have proposed a specific metric by which variations in surface depth could be perceptually distınguished-namely, the area under the Width $\times$ Position curve. This proposed metric corresponds quite closely to the observers' judgments in all four exper1ments. It is best to be particularly cautious regarding this issue, however, because we have no theoretical justification of the proposed area measure, and there are many other possible metrics

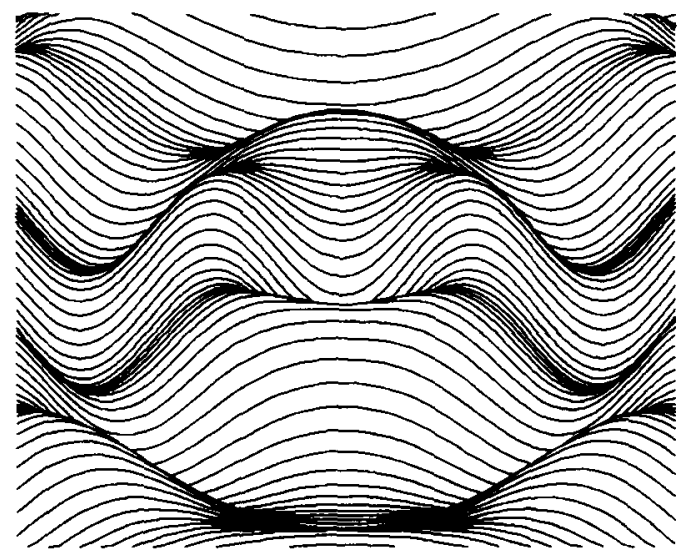

Figure 20 The same surface as in Figure 19 depicted with contour information 
that could conceivably be used to describe how element width varies as a function of position. We would not be surprised, therefore, if some other metric turns out to provide equally good fits of the data.

It is interestıng to note, while evaluating the spatıal distribution of element widths as a potential source of information, that such variations have not been considered in previous investigations. Most of the early work on perceived slant from texture was designed to determine the relative perceptual salience of a small number of optical variables-specifically, element length, compression, and density. Although element widths were not directly manipulated in these experiments, they would have been affected indirectly by changes in element length and compression, both of which had significant effects on observers' slant judgments Thus, it is quite possible that global variations in element width may also be a primary source of information for the perception of planar surfaces.

\section{What Do Observers "See" in a Textured Display?}

Our discussion thus far has focused primarily on identifying the particular aspects of optical texture from which observers perceive the three-dimensional structures of curved surfaces, but we have not yet considered the equally important problem of what exactly is specified by that information This is an issue of considerable relevance to current perceptual theory. One popular hypothesis adopted by Gibson (1950a) early in his career and much later by Marr (1982) is that the percelved metric structure of a surface is defined by 1 ts local depth and orientation relative to the point of observation. Note that there are many aspects of this hypothesis that need to be considered. Is the percelved structure of a surface metric or nonmetric? What are its specific properties (e.g., depth or orientation)? Are they defined locally or globally? And are they defined in a vewercentered space relative to the point of observation or in an object-centered space relative to other parts of the same surface?

It is important to keep in mind when evaluating these issues that there is an indefinite number of potential descriptors for objects and events in a natural environment. The most commonly used properties for describing surfaces_namely, depth, orientation, and curvature-were all originally invented by geometers and need not be accepted by default as the appropriate descriptors for perceptual psychology (see Gıbson, 1979, for an extensive discussion of this issue). Although the results of the present experiments seem to suggest that surface "depth" is a perceptually meaningful concept, there is no reason to assume a priori that its psychological meaning is synonymous with its usage in analytic geometry (e.g., as argued by Marr, 1982).

In addition to their theoretical stgnificance, these issues also have important methodological implications. In any psychophysical investigation of three-dimensional form perception, the observers must be asked a specific question about the perceived structure of the stimulus displays For example, they might be asked to make judgments of percerved slant (e g., Gibson, 1950a) or perceived curvature (e.g., Todd \& Mingolla, 1984) or percelved depth, as in the present experiments. In deciding upon which question to ask, a researcher makes an implicit assumption about which descriptors of the environment are psychologically appropriate (see Runeson, 1977). All too often, however, the chosen descriptors are based on Cartesian analytic geometry, with little or no justification except for tradition.

There are other ways of describing surface layout that do not require a point-by-point estimate of depth and/or orientation. For example, in his own attempt to address this issue, Gibson (1979) focused on the nonmetric structure of surface layouts. Concavities and convexities, he argued, are unitary features of surface layout that cannot be broken down into elementary $1 \mathrm{~m}$ pressions of slant or depth. Gibson was not alone in reaching this conclusion. A similar emphasis on the nonmetric structure of surface layout can also be found in the empirical work of Cuttıng and Millard (1984) and in the computational analyses of Koenderink and van Doorn (1980, 1982).

If these conclusions are correct, then a more appropriate psychophysical procedure for studying the perception of surface layout would be to ask observers to identify the hills and valleys within a more complex terrain. In an effort to develop such a procedure, we have recently begun to investigate observers' perceptıons of visual displays depıctıng a wider variety of surface undulations. We have observed, however, that the perception of three-dimensional form from randomly distributed patterns of granular texture tends to break down if the depicted surface is too complex. For example, Figure 19 shows a complex, undulating surface, which has been covered whth texture elements using the same procedure as described for the present exper1ments. Although the three-dimensional form of this surface may be discernible with close inspection, the overall perceptual effect is not compelling. For the sake of comparison, an ident1cal surface is depicted in Figure 20 using a pattern of contours The perceptual effect in this case is quite strikıng. Indeed, for surfaces depicted with contour patterns (or shading), the overall perceptual salıence of a display tends to increase with surface complexity.

Although all of the discussion thus far has been concerned exclusively with patterns of optical texture presented in isolation, it is important to point out that such a limited form of stımulation could seldom, if ever, be achieved under more natural viewing conditions In natural vision, there would generally be other sources of information avalable such as shading, motion, or binocular disparity. How these different aspects of opt1cal structure interact with one another to form a unitary perception of the surrounding environment remains an important problem for future research.

\section{References}

Braunstein, M L (1976). Depth perceptıon through motıon New York Academic Press.

Braunstein, M L , \& Payne, J W (1969) Perspective and form ratio as determunants of relatıve slant judgments Journal of Experimental Psychology, 81, 584-590

Cutting, J. E., \& Millard, R. T (1984). Three gradients and the perception of flat and curved surfaces Journal of Experimental Psychology General, 113, 198-216

Gibson, J J (1947) Motion picture testing and research (Avation Psychology Research Reports, No 7, pp 179-195) Washıngton, DC U S Government Printıng Office

Gibson, J J (1950a) The perception of visual surfaces American Journal of Psychology, 63, 367-384 
Gibson, J J (1950b) The perception of the visual world Boston Houghton Mifflin

Gibson, J J (1979) The ecological approach to visual perception Boston Houghton Mifflin

Grossberg, S , \& Mingolla, E (1985a) Neural dynamics of form perception Boundary completion, Illusory figures, and neon color spread1ng Psychological Review, 92, 173-211

Grossberg, S , \& Mingolla, E (1985b) Neural dynamics of perceptual grouping Textures, boundaries, and emergent segmentations Perception \& Psychophysics, 38, 141-171

Grossberg, S, \& Mingolla, E (in press) Neural dynamics of surface perception Boundary webs, illuminants and shape from shading. Computer Vision, Graphics, and Image Processing

Koenderink, J J , \& van Doorn, A J (1980) Photometric invariants related to solıd shape Optica Acta, 27, 981-996

Koenderink, J J , \& van Doorn, A J (1982) The shape of smooth objects and the way contours end Perception, 11, 129-137

Marr, D (1982) Vision San Francisco, CA W H Freeman

Pentland, A (1983) Fractal-based description of natural scenes IEEE Transactions on Pattern Analysis \& Machine Vision, 1, 201-209

Purdy, W C (1958) The hypothesis of psychophysical correspondence
In space perception Dissertation Abstracts International, 19, 14541455 (University Microfilms No 58-5594)

Runeson, S. (1977) On the possibility of "smart" perceptual mechanisms Scandinavian Journal of Psychology, 18, 172-179

Stevens, K A (1981) The information content of texture gradients Biological Cybernetics, 42, 95-105

Stevens, K A (1984) On gradients and texture "gradients" Journal of Experimental Psychology General, 113, 217-220

Todd, J T (1984) Formal theories of visual information In W H Warren \& $\mathrm{R}$ E Shaw (Eds), Persistence and Change Proceedings from the First International Conference on Event Perception (pp 87-102) Hillsdale, NJ Erlbaum

Todd, J T, \& Mingolla, E (1983) Perception of surface curvature and direction of illumination from patterns of shading Journal of Expertmental Psychology Human Perception and Performance, 9. 583-595

Todd, J. T, \& Mingolla, E (1984) Simulations of curved surfaces from patterns of optical texture Journal of Experimental Psychology $\mathrm{Hu}$ man Perception and Performance, 10, 734-739

Witkın, A P. (1981) Recoverıng surface shape and orientation from texture Artificial Intelligence, 17, 17-45

Received July 21, 1986

Revision received October 9, 1986 